\title{
Preference and understanding of two different graphic displays of the Mediterranean diet
}

\author{
E. Turbett, J. Lara and J. C. Mathers \\ Human Nutrition Research Centre, Institute for Ageing and Health, Newcastle University, William Leech Building, \\ Framlington Place. Newcastle Upon Tyne, NE2 4HH, UK
}

There is now strong evidence indicating that a Mediterranean-type diet (MD) comprising higher intakes of vegetables, fruits, legumes, cereals, fish and a moderate intake of red wine during meals, is associated with a lower risk for chronic diseases and improved wellbeing $^{(1)}$. The MD is often depicted as a pyramid-shape model. However, preference for, and understanding of, different graphic models for representation of the MD, particularly in countries where local guidelines use a different model (e.g. the UK, where a plate-shaped model, the eatwell plate, is used) ${ }^{(2)}$, has not been reported previously.

The present pilot study is part of LiveWell, a research programme to develop lifestyle-based interventions to improve healthy ageing at the peri-retirement period. The study aimed to compare preference and understanding of pyramid- and plate-based models of the MD. Thirty healthy subjects, aged $69 \pm 6$ years, recruited from among the general public, completed a questionnaire on demographics, general health, and lifestyle, and attended a $1.5 \mathrm{~h}$ group session. This session described the characteristics and benefits of the MD before evaluating the two graphic displays. We also assessed participants understanding of the MD guidelines and their ability to translate these into meals. Results are presented in the table below.

\begin{tabular}{lcrrr}
\hline & & \multicolumn{2}{c}{ Graphic display } & \\
& Sample & Pyramid & Plate & $P$ value \\
\hline Preference for a display & 30 & $12(40)$ & $18(60)$ & 0.27 \\
Aware of UK eatwell plate (graphic display) & 17 & $5(29)$ & $12(71)$ & 0.09 \\
Unaware of UK eatwell plate (graphic display) & 13 & $7(54)$ & $6(46)$ & 0.78 \\
Women & 21 & $10(48)$ & $11(52)$ & 0.83 \\
Men & 9 & $2(22)$ & $7(78)$ & 0.10 \\
Age $\leq 68$ years & 17 & $8(47)$ & $9(53)$ & 0.81 \\
Age $\geq 69$ years & 13 & $4(31)$ & $9(69)$ & 0.17 \\
\hline
\end{tabular}

Values are frequencies (percentage). $P$ values for Chi-square Goodness-of-fit test using Minitab 15.1.

In conclusion, among older people in the UK, a greater proportion preferred a plate-shaped to a Pyramid-shaped graphic display of the MD, but the difference was not statistically significant. However, factors such as awareness of current national guidelines (i.e. the UK eatwell plate) might influence the acceptability and understanding of a different shape-model such as the pyramid. The findings from this pilot study may be useful in developing dietary interventions promoting the MD within the UK.

LiveWell is supported by the Lifelong Health and Wellbeing Cross-Council Programme (LLHW). The LLHW funding partners are: Biotechnology and Biological Sciences Research Council, Engineering and Physical Sciences Research Council, Economic and Social Research Council, Medical Research Council, Chief Scientist Office of the Scottish Government Health Directorates, National Institute for Health Research/The Department of Health, The Health and Social Care Research \& Development of the Public Health Agency (Northern Ireland), and Wales Office of Research and Development for Health and Social Care, Welsh Assembly Government.

1. Sofi F, Abbate R, Gensini GF, Casini A (2010) Accruing evidence on benefits of adherence to the Mediterranean diet on health: an updated systematic review and meta-analysis. Am J Clin Nutr 92, 1189-1196.

2. Food Standards Agency (UK-FSA). http://www.food.gov.uk/scotland/scotnut/eatwellplate/ 